\title{
Distinct pathways to persuasion: The role of affect in message-framing effects
}

Citation for published version (APA):

van 't Riet, J., Ruiter, R. A. C., Werrij, M. Q., Candel, M. J. J. M., \& de Vries, H. (2010). Distinct pathways to persuasion: The role of affect in message-framing effects. European Journal of Social Psychology, 40(7), 1261-1276. https://doi.org/10.1002/ejsp.722

Document status and date:

Published: $01 / 12 / 2010$

DOI:

10.1002/ejsp.722

Document Version:

Publisher's PDF, also known as Version of record

Document license:

Taverne

Please check the document version of this publication:

- A submitted manuscript is the version of the article upon submission and before peer-review. There can be important differences between the submitted version and the official published version of record.

People interested in the research are advised to contact the author for the final version of the publication, or visit the DOI to the publisher's website.

- The final author version and the galley proof are versions of the publication after peer review.

- The final published version features the final layout of the paper including the volume, issue and page numbers.

Link to publication

\footnotetext{
General rights rights.

- You may freely distribute the URL identifying the publication in the public portal. please follow below link for the End User Agreement:

www.umlib.nl/taverne-license

Take down policy

If you believe that this document breaches copyright please contact us at:

repository@maastrichtuniversity.nl

providing details and we will investigate your claim.
}

Copyright and moral rights for the publications made accessible in the public portal are retained by the authors and/or other copyright owners and it is a condition of accessing publications that users recognise and abide by the legal requirements associated with these

- Users may download and print one copy of any publication from the public portal for the purpose of private study or research.

- You may not further distribute the material or use it for any profit-making activity or commercial gain

If the publication is distributed under the terms of Article $25 \mathrm{fa}$ of the Dutch Copyright Act, indicated by the "Taverne" license above, 
European Journal of Social Psychology

Eur. J. Soc. Psychol. 40, 1261-1276 (2010)

Published online 8 December 2009 in Wiley Online Library

(wileyonlinelibrary.com) DOI: 10.1002/ejsp.722

Research article

\title{
Distinct pathways to persuasion: The role of affect in message-framing effects
}

\author{
JONATHAN VAN 'T RIET ${ }^{*}$, ROBERT A. C. RUITER ${ }^{2}$, \\ MARIEKE Q. WERRIJ' ${ }^{2}$ MATH J. J. M. CANDEL ${ }^{3}$ AND \\ HEIN DE VRIES ${ }^{4}$ \\ ${ }^{1}$ Agricultural Economics Research Institute, Wageningen \\ University and Research Centre, The Netherlands \\ ${ }^{2}$ Department of Work and Social Psychology, Faculty of \\ Psychology and Neuroscience, Maastricht University, The \\ Netherlands \\ ${ }^{3}$ Department of Methodology and Statistics, School for Public \\ Health and Primary Care (CAPHRI), Maastricht University, The \\ Netherlands \\ ${ }^{4}$ Department of Health Promotion, School for Public Health and \\ Primary Care (CAPHRI), Maastricht University, The Netherlands
}

\section{Abstract}

Health-promoting messages can be framed in terms of the gains that are associated with healthy behaviour (gain frame) or the losses that are associated with unhealthy behaviour (loss frame). In the present research, we examined the role of positive and negative affect in the persuasive effects of gain-and loss-framed health-promoting information. Experiment 1 $(N=98)$ showed that gain-framed information resulted in higher levels of information acceptance than loss-framed information and that this effect was mediated by positive affect. The results of Experiment $2(N=129)$ showed that gainframed information resulted in higher levels of information acceptance and attitude, an effect that was again mediated by positive affect. In addition, loss-framed information resulted in more negative affect than gain-framed information and negative affect increased participants' intention to engage in the healthy behaviour. These results suggest that affect may be of great importance in the persuasion process and may be particularly helpful to explain the underlying mechanisms of message framing effects. The findings also suggest that gain- and loss-framed messages offer distinct pathways to persuasion. Copyright (C) 2009 John Wiley \& Sons, Ltd.

\section{DISTINCT PATHWAYS TO PERSUASION: THE ROLE OF AFFECT IN MESSAGE-FRAMING EFFECTS}

Health promoting messages usually stress the value of healthy behaviour, but they can do this in several ways. In particular, the message can be framed in terms of the benefits of engaging in the healthy behaviour (gain frame) or in terms of the costs of failing to engage in the healthy behaviour (loss frame). Research has shown that these frames can have a different persuasive impact, even when the different frames are applied to objectively equivalent information (see for instance Gerend \& Cullen, 2008; O'Keefe \& Jensen, 2006; Rothman \& Salovey, 1997; Van 't Riet, Ruiter, Werrij, \& De Vries, 2008). Unfortunately, studies show inconsistent results with regard to which type of framing is more persuasive (O'Keefe \&

*Correspondence to: Jonathan van 't Riet, MSc, Agricultural Economics Research Institute, Wageningen University and Research Centre, P.O. Box 29703, 2502 LS The Hague, The Netherlands. E-mail: jonathan.vantriet@wur.nl 
Jensen, 2006). To account for the inconsistent findings in the literature, one influential approach to the study of message framing has been to focus on the function of the recommended behaviour, making a distinction between behaviours that serve to prevent an illness (like exercising or quitting smoking) and behaviours that serve to detect an illness (like skin selfexamination or obtaining a mammography). According to Rothman and Salovey (1997), people perceive diseaseprevention behaviours as relatively safe, because they minimize the chance of falling ill. In contrast, people perceive disease-detection behaviours as inherently risky because they entail the possibility of finding out that one is ill. Drawing from Prospect Theory (Kahneman, 2003; Kahneman \& Tversky, 1984), Rothman and Salovey (1997) go on to suggest that gain-framed information is more persuasive when advocating disease-prevention behaviours, because gain-framed information makes people risk-averse and thus more likely to engage in relatively safe disease-prevention behaviours. In contrast, they suggest that loss-framed information is more persuasive for disease-detection behaviours, because lossframed information makes people willing to take risks and thus more likely to engage in relatively risky disease-detection behaviours. A recent meta-analysis showed, however, that for behaviours serving to detect an illness, gain- and loss-framed messages were not differentially persuasive (O'Keefe \& Jensen, 2006). For behaviours serving to prevent an illness, a small advantage of gain-framed information was found, although this effect seemed mainly due to a limited amount of studies on dental health (O'Keefe \& Jensen, 2007). Thus, in contrast to Rothman and Salovey's reasoning, and despite an impressive body of literature, it is currently unclear how health-care professionals should frame persuasive messages.

In the present research, we tried to shed some light on the inconsistent findings in the message-framing literature by investigating the underlying mechanisms of framing effects. Because finding no differential effects of message framing might obscure the fact that different, but equally potent mechanisms might underlie the effects of gain- and loss-framed information (Shen \& Dillard, 2007), we tried to investigate the pathways through which gain- and loss-framed information exert their influence on persuasion. Research has shown that gain-framed information evokes positive feelings in the recipient and that loss-framed information evokes negative feelings (e.g. Shen \& Dillard, 2007). In the present paper, we propose that positive and negative affect can both contribute to persuasion.

\section{The Role of Affect}

Contemporary theories of emotion state that affect results from an appraisal of the relationship between one's goals and the environment. This appraisal yields positive affect when an individual perceives that the environment is congruent with his or her goals. In contrast, when an individual judges that the environment is in an incongruent relationship with his or her personal goals, the individual experiences negative affect (for overviews see Frijda, 1986; Lazarus, 1991). The purpose of affect is to induce states of 'action readiness' that make the individual responsive to the environment or context (Frijda, 2007). As Shen and Dillard (2007) point out, gain-framed health-promoting messages focus on beneficial outcomes, emphasizing possible congruence between the recipient's goals and the environment/situation. Loss-framed health promoting messages, on the other hand, focus on costs and by doing so emphasize possible incongruence between goals and the environment/situation. For this reason, we expect gain-framed information to elicit more positive affect than lossframed information, and loss-framed information to elicit more negative affect than gain-framed information. The limited research that exists on the relationship between framing and affect is consistent with our logic (Chang, 2005; Cox, Cox \& Zimet, 2006; Cox \& Cox, 2001; Millar \& Millar, 2000; Schneider et al., 2001a; Shen \& Dillard, 2007).

The idea that affect plays a crucial role in persuasion has a long history in Western thought. According to Aristotle, there are three means of persuasion: The use of logic, the moral character of the speaker and the elicitation of emotion in the listener (Carey, 1994). In more recent years, several scholars have studied the effects of message-induced affect on persuasion. One theoretical account of the relationship between message-induced affect and persuasion stems from marketing and consumer psychology and is called the 'affect transfer hypothesis' (MacKenzie, Lutz, \& Belch, 1986). According to this account, advertisements that evoke positive affect result in a positive attitude towards the ad, which in turn results in a positive attitude towards the advertised brand. A meta-analysis of persuasion studies in the field of marketing showed support for this hypothesis (Brown, Homer, \& Inman, 1998).

Negative affect has also drawn attention from persuasion scholars. Numerous studies tested the effects of fear appeals on measures of attitude, intention and behaviour (for overviews see Eagly \& Chaiken, 1993; Ruiter, Abraham, \& Kok, 2001). A fear appeal is a persuasive message attempting to arouse fear to promote precautionary motivation and selfprotective action (Rogers, 1983). Meta-analyses of the fear-persuasion relationship have shown that evoking fear can enhance a message's persuasive power (Mongeau, 1998; Witte \& Allen, 2000; but see also Ruiter et al., 2001). With 
regards to framed messages, the persuasive effects of positive and negative affect imply that gain- and loss-framed messages exert their influence on persuasion to a large extent through quite different substrates (positive versus negative affect; see also Cacioppo \& Berntson, 1994).

Based on the reasoning outlined above, we hypothesized that gain-framed information gives rise to greater levels of positive affect than loss-framed information, whereas loss-framed information gives rise to greater levels of negative affect. We furthermore hypothesized that positive and negative affect can both contribute to persuasion.

\section{Mood and Persuasion}

There is an extensive body of literature available on the influence of affect on information processing and decision making and several theoretical frameworks have been proposed to account for the empirical findings (e.g. Bless \& Schwartz, 1999; Forgas, 1995; Isen, Daubman, \& Nowicki, 1987; Isen, Nygren, \& Ashby, 1988). Most of this research, however, has focused on the effects of moods. In a typical experiment, mood is induced by having participants watch either a happy or sad videotape (e.g. Forgas, 2007), or a positive mood is induced by giving participants a small bag of candies (e.g. Isen et al., 1987), after which happy and sad participants (or happy participants and participants in a neutral mood) engage in the experimental task. There is reason to believe that mood is particularly likely to exert effects on people's thoughts and behaviour when individuals are unaware of the source of their affect (Sinclair, Mark, \& Clore, 1994). According to Schwarz and Clore (2003; p. 299-300): 'What renders the influence of moods highly pervasive is that their source is usually not in the focus of our attention'. In the present research, we will not focus on moods, but on what Dillard and Meijnders (2002) call 'message-induced affect', affect that is a product of the message itself and that is most likely to be consciously perceived by recipients as arising from processing the persuasive message. Dillard and Meijnders state that message-induced affect differs from 'message-irrelevant affect', such as moods, which bears no logical relationship to the content of the message and is mainly influential when people are not aware of its source.

\section{The Present Research}

We conducted two experiments to test whether framing exerts its effects on persuasion through positive and negative affect. In Experiment 1, we used framed information about physical activity, assessing acceptance of the information as the outcome measure. In Experiment 2, we used framed information about reducing salt intake, assessing information acceptance, attitude and intention as the outcome measures. Our hypotheses were that gain-framed information would result in more positive affect than loss-framed information (Hypothesis 1) and that positive affect would mediate the persuasiveness of gain-framed information (Hypothesis 2). In addition we hypothesized that loss-framed information would result in more negative affect than gain-framed information (Hypothesis 3 ) and that negative affect would mediate the persuasiveness of loss-framed information (Hypothesis 4).

\section{EXPERIMENT 1}

\section{Method}

\section{Participants}

Ninety-eight students at Maastricht University voluntarily participated in the experiment.

\section{Procedure and Design}

Participants were recruited in the university restaurant buildings. Students who were sitting at one of the restaurant tables during lunchtime were eligible to participate. Participants were asked to fill in a questionnaire, containing questions on 
physical activity. These students received a booklet containing a written introduction of the experiment and the questionnaire, which, following previous studies in which framing effects were found as a result of framed information that consisted of no more than a few statements (Broemer, 2004), consisted of six pages in which six statements concerning physical activity were used as the framed material. The six pages each started with a statement, followed by seven questions that assessed the extent to which the statement elicited positive and negative affect and participants' acceptance of the statement. In the gain-framed information condition, all six statements were gain-framed, whereas in the lossframed information condition, all six statements were loss-framed. For instance, in the gain-framed [loss-framed] information condition two statements read: 'If I am [in]sufficiently active, my muscles will stay strong [become weak]' and 'If I am [in]sufficiently active, my immunity will increase [suffer], so it will be easier to stay healthy [harder to fight of diseases]'. Pilot studies showed that these statements were judged as credible. To avoid sequence-effects the order of the six statements was varied randomly. The experiment used a one-factorial (frame: gain versus loss) between-participants design.

\section{Outcome Measures}

For each statement, two items assessed positive affective reactions to the statement and two items assessed negative affective reactions, using 10-point semantic differentials. The positive affect items assessed the extent to which participants thought the statement made them feel happy $(1=$ Very happy; $10=$ Not happy at all $)$ and made them feel relieved $(1=$ Very relieved; $10=$ Not relieved at all $)$. Scores on these items were reversed, such that a high score reflected a positive subjective feeling and then combined to create an average positive affect score. The internal consistencies of these scales were calculated for all six statements separately, and ranged from Cronbach's $\alpha=.69$ to $\alpha=.86$. The average internal consistency over all six statements was $\alpha=.78$.

The negative affect items assessed the extent to which participants thought the statement made them feel sad $(1=$ Very sad; $10=$ Not sad at all $)$ and afraid $(1=$ Very afraid; $10=$ Not afraid at all $)$. Scores on the sad and afraid items were reversed and combined to create an average negative affect score. The average internal consistency over all six statements was $\alpha=.75$ (range: $\alpha=.61-\alpha=.85$ ). Correlations between positive and negative affect ranged from $r=-.22$ to $r=.13$. The overall correlation between the two affect variables was $r=-.07, p=.09$.

Three items assessed information acceptance by asking participants to indicate for each statement the extent to which they agreed with the statement $(1=I$ totally agree; $10=I$ totally disagree $)$, felt that the statement was exaggerated $(1=$ Very exaggerated $; 10=$ Not at all exaggerated $)$, and thought the statement was relevant $(1=$ Very relevant $; 10=$ Not at all relevant). After we reversed the scores on the agreement and relevance items, the scores on the three items were averaged to create an average information acceptance score for each statement. The average internal consistency over all six statements was $\alpha=.79$ (range: $\alpha=.66-\alpha=.84$ ).

\section{Statistical Analysis}

First, correlations between positive affect, negative affect and information acceptance were investigated. Second, the effect of frame on affect and information acceptance was investigated, using linear multilevel analyses to account for the fact that the measures of negative and positive affect were clustered within individuals. Third, we performed mediation analyses to test our hypothesis that positive and negative affect mediated the persuasive effects of message framing. In these analyses, frame was coded as $0=$ gain frame, $1=$ loss frame. In addition, five dummy variables indicating the statement were generated and entered into all linear multilevel analyses (dummy 1 was coded as $1=$ statement 2, $0=$ else; dummy 2 was coded as $1=$ statement 3, $0=$ else; dummy 3 was coded as $1=$ statement $4,0=$ else; dummy 4 was coded as $1=$ statement $5,0=$ else; dummy 5 was coded as $1=$ statement $6,0=$ else). Since they are not of central concern for the present research, results for these dummy variables will not be reported in this paper. We used the module Mixed Linear Models within the software package SPSS 13.0. 


\section{Results}

\section{Correlations}

As can be seen in Table 1, information acceptance was positively correlated with positive affect, but not with negative affect. Positive and negative affect were not significantly correlated.

\section{Results of the Linear Multilevel Analyses}

Gain-framed statements elicited more positive affect than loss framed statements, supporting Hypothesis $1\left(M_{\text {gain }}=5.82\right.$, $\left.\mathrm{SD}_{\text {gain }}=2.04 ; M_{\text {loss }}=4.78, \mathrm{SD}_{\mathrm{loss}}=1.41\right)$, and less negative affect, supporting Hypothesis $2\left(M_{\text {gain }}=2.57, \mathrm{SD}_{\text {gain }}=1.71\right.$; $\left.M_{\text {loss }}=3.42, \mathrm{SD}_{\text {loss }}=1.91\right)$. Also, gain-framed statements resulted in higher levels of information acceptance than lossframed statements $\left(M_{\text {gain }}=7.27, \mathrm{SD}_{\text {gain }}=1.83 ; M_{\text {loss }}=5.94, \mathrm{SD}_{\text {loss }}=2.23\right)($ see Table 2$)$.

\section{Mediation Analyses}

Mediation analyses were performed to investigate whether the effect of frame on information acceptance was mediated by positive and/or negative affect. In the approach for identifying mediators outlined by Baron and Kenny (1986), a variable functions as a mediator when (1) the independent variable has a significant effect on the mediator, (2) the independent variable has a total effect on the dependent variable, (3) the mediator is significantly associated with the dependent variable when the other independent variables are controlled for and (4) the effect of the independent variable on the dependent variable is reduced when the mediator is entered into the model.

Table 2 shows that frame had a significant effect on positive affect and information acceptance. To test whether positive affect had a significant effect on information acceptance while frame was controlled for, another mixed linear model analysis was conducted with frame and positive affect as independent variables and information acceptance as the dependent variable. In this analysis, positive affect had a significant effect on information acceptance, $B=.22, t=4.60$, $p<.001$, whereas the effect of frame on information acceptance was reduced, $B=.89, t=4.05, p<.001$ (from a total effect of $B=-1.31$; see Table 2). This suggests that the effect of frame on information acceptance is at least partly mediated by positive affect, which is in line with Hypothesis 2. A Sobel's Z-test (i.e. the Aroian version of the Z-test; Baron $\&$ Kenny, 1986) revealed that the mediation was significant, $\mathrm{Z}=2.76, p<.01$.

Table 1. Correlations (range of correlations computed for the six statements separately) between positive affect, negative affect and information acceptance

\begin{tabular}{lrr}
\hline & Positive affect & Negative affect \\
\hline Negative affect & $-.07(-.22-.13)$ & - \\
Information acceptance & $.27^{* *}(.20-.47)$ & $.06(-.21-.24)$ \\
\hline
\end{tabular}

${ }^{* *} p<.01$.

Table 2. Results of the linear multilevel analyses: Effects of frame on positive affect, negative affect and information acceptance

\begin{tabular}{lcr}
\hline & \multicolumn{2}{c}{ Effect of frame $^{\mathrm{a}}$} \\
\cline { 2 - 3 } & \multicolumn{1}{c}{$B$} & SE $B$ \\
\hline Positive affect & $-1.01^{*}$ & .29 \\
Negative affect & $.83^{*}$ & .30 \\
Information acceptance & $-1.31^{* *}$ & .23 \\
\hline
\end{tabular}

${ }^{\mathrm{a}}$ Coded as $0=$ gain frame, $1=$ loss frame. ${ }^{*} p<.01 ;{ }^{* *} p<.001$. 
Table 2 also shows that frame had a significant effect on negative affect. To test whether negative affect had a significant effect on information acceptance while frame was controlled for, another mixed linear model analysis was conducted. In this analysis, negative affect did not have a significant effect on information acceptance when controlled for frame, $B=.07, t=1.45, p=.08$. Thus, Hypothesis 4 was not supported.

\section{Discussion and Introduction to Experiment 2}

The results of Experiment 1 showed that individuals found gain-framed information about physical activity more acceptable than loss-framed information, and that positive affect mediated this effect. This supports Hypotheses 1 and 2 and suggests that positive affect can be of great importance in the persuasion process. Although loss-framed information evoked higher levels of negative affect than gain-framed information, we did not find evidence that negative affect had an effect on information acceptance. However, this failure to find support for Hypotheses 4 might be caused by the limitations of Experiment 1. For one, the research setting of Experiment 1 (the university restaurant during lunchtime) limited experimental control and although we instructed participants to fill out the questionnaires individually, we cannot be sure that all participants refrained from communicating with each other during the procedure. Second, although perceived effectiveness, a measure akin to information acceptance, has been shown to be substantially correlated with actual effectiveness (Dillard, Weber, \& Vail, 2007), finding effects of framing on information acceptance is less relevant than, for instance, finding effects on attitude or intention. Moreover, it is possible that positive and negative affect have different effects on different outcome measures.

According to Fredrickson and Losada (2005), positive and negative emotions both have adaptive value, but in a different way. Positive emotions can broaden people's mindsets, expanding cognition and behavioural tendencies (Fredrickson \& Branigan, 2005). This may account for the fact that participants in the gain-framed condition were more 'open' to the health-promoting information. One might also hypothesize that this openness leads to a more positive attitude towards the recommended behaviour, which is supported by findings from the marketing literature that suggest that positive affect resulting from the persuasive information can contribute to a positive attitude towards the advertised brand (Brown et al., 1998). Negative emotions, on the other hand, narrow people's behavioural urges towards specific actions, preparing the body physically and mentally for immediate action (Fredrickson and Losada, 2005; see also Frijda's (2007) conceptualization of action readiness). Thus, negative affect as a consequence of loss-framed information, might exert a motivating influence more directly on intention. Some evidence for this comes from studies in which participants' selfreported negative affect after reading a health-promoting message was significantly correlated with intention, but not with attitude (De Hoog, Stroebe, \& De Wit, 2008, Experiment 2; Witte, 1994).

To obtain a clearer picture of the role of positive and negative affect in message-framing effects, we used gain- and lossframed messages about reducing salt intake in Experiment 2 and assessed positive affect, negative affect, information acceptance, attitude and intention. Our hypotheses for Experiment 2 were that gain-framed information would result in more positive affect than loss-framed information (Hypothesis 1) and that positive affect would mediate the effect of gainframed information on information acceptance and attitude (Hypothesis 2). In addition we hypothesized that loss-framed information would result in more negative affect than gain-framed information (Hypothesis 3), and that negative affect would mediate the effect of loss-framed information on intention (Hypothesis 4). To increase experimental control, we conducted Experiment 2 in our research lab.

\section{EXPERIMENT 2}

\section{Method}

\section{Participants}

One hundred and twenty-nine students at Maastricht University voluntarily participated in the experiment in exchange for $€ 10$. Most of the participants were female (114 versus 15 males). Age ranged from 17 to 25 years, with a mean age of 20.1 years $(\mathrm{SD}=1.7)$. 


\section{Procedure and Design}

Participants were seated in individual booths and were told that they were about to participate in a study aimed at testing health education materials that had been designed to be used 'on the Internet'. First, participants' demographics and baseline intention to reduce salt intake were assessed. Next, participants were provided with a persuasive communication about reducing salt intake, which was either gain- or loss-framed. After reading the persuasive communication, participants completed the dependent measures, were debriefed and received their fee. This study used a one-factorial (frame: gain versus loss) between-participants design.

\section{Baseline Measures}

We assessed participants' intentions to reduce their salt-intake at baseline, using two items. One item asked participants to indicate whether they intended to reduce their salt intake in the coming week $(1=$ No, certainly not; $7=$ Yes, certainly $)$ and one item asked participants to indicate whether they intended to reduce their salt intake in the future $(1=$ No, certainly not; $7=$ Yes, certainly). An average baseline intention score was created $(M=2.85, \mathrm{SD}=1.13 ; \alpha=.86)$, which was centered and used in the analyses as a covariate.

\section{Framed Communication}

The persuasive communication consisted of a short message about either the positive consequences of reducing the amount of salt in one's diet or the negative consequences of not reducing the amount of salt in one's diet. The gain-framed message contained 195 words and the loss-framed message contained 180 words. The full texts are available in Appendix A.

\section{Outcome Measures}

Four items assessed positive reactions to the information (positive affective reactions) and four items assessed negative reactions (negative affective reactions). The positive affect items assessed the extent to which participants thought the information made them feel happy $(1=$ Very happy; $7=$ Not at all happy $)$, relieved $(1=$ Very relieved; $7=$ Not at all relieved $)$, optimistic $(1=$ Very optimistic $; 7=$ Not at all optimistic $)$, and content $(1=$ Very content $; 7=$ Not at all content $)$. Scores were reversed and combined to create an average positive affect score $(\alpha=.84)$. The negative affect items assessed the extent to which participants thought the information made them feel sad $(1=$ Very sad; $7=$ Not at all sad $)$, afraid $(1=$ Very afraid; $7=$ Not at all afraid $)$, tense $(1=$ Very tense; $7=$ Not at all tense $)$, and uncomfortable $(1=$ Very uncomfortable; $7=$ Not at all uncomfortable). Scores were reversed and combined to create an average negative affect score $(\alpha=.86)$.

Eight items assessed information acceptance by asking participants to indicate the extent to which they thought the information was convincing $(1=$ Very convincing; $7=$ Not at all convincing $)$, relevant $(1=$ Very relevant $7=$ Not at all relevant $)$, realistic $(1=$ Very realistic; $7=$ Not at all realistic $)$, useful $(1=$ Very useful $7=$ Not at all useful $)$, interesting $(1=$ Very interesting; $7=$ Not at all interesting $)$, true $(1=$ Very true; $7=$ Not at all true $)$ and exaggerated $(1=$ Very exaggerated $7=$ Not at all exaggerated). Furthermore, one item asked participants to indicate the extent to which participants agreed with the information $(1=I$ totally agree; $7=I$ totally disagree $)$. After we reversed the scores of all items except the exaggerated item, the scores on the eight items were averaged to create an average information acceptance score $(\alpha=.78)$.

Six items were used to assess attitude towards eating less salt, asking participants to indicate the extent to which they rated eating less salt as (1) Very good versus (7) Very bad, (1) Very healthy versus (7) Very unhealthy, (1) Very tasty versus (7) not at all tasty, (1) Very much worth the effort versus (7) not worth the effort at all, (1) Very important versus (7) Very unimportant and (1) Very sensible versus (7) not sensible at all. After scores on the attitude items were reversed, an average score was created $(\alpha=.81)$. 
Six items were used to assess intention to eat less salt. One item asked participants 'how likely is it that you will eat less salt in the future?' $(1=$ Very likely; 7 = Very unlikely). One item asked participants: 'How likely is it that you will eat less salt in the coming week?' ( 1 =Very likely; $7=$ Very unlikely). Two items asked participants whether they planned to eat less salt in the future and in the coming week. One item asked participants whether they considered eating less salt in the future and one item asked participants whether they were sure that they would eat less salt in the coming week. These four items used a 7-point scale $(1=$ Certainly; $7=$ Certainly not $)$. Scores on the intention items were reversed and an average intention score was calculated $(\alpha=.94)$.

\section{Statistical Analysis}

First, correlations between all relevant variables were investigated. Second, linear regression analyses tested the effect of frame (coded as $0=$ gain frame, $1=$ loss frame) on positive affect, negative affect, information acceptance, attitude and intention. Baseline intention was entered into the analyses as a covariate. Third, relations between relevant variables were investigated using Structural Equation Modelling. Fourth, mediation analyses were performed to formally test our hypotheses with regards to mediation. For all analyses except the Structural Equation Modelling analyses, the used statistical package was SPSS 13.0. For the Structural Equation Modelling analyses we used the package M-Plus version 3.11 .

\section{Results}

\section{Correlations}

Positive and negative affect had a significant, negative correlation. Furthermore, positive affect was significantly correlated with information acceptance and attitude, whereas negative affect was significantly correlated with intention (see Table 3).

\section{Regression Analyses}

Results of the linear regression analyses showed that gain-framed messages evoked more positive affect than loss-framed messages $\left(M_{\text {gain }}=4.63, \mathrm{SD}_{\text {gain }}=.80 ; M_{\text {loss }}=4.23, \mathrm{SD}_{\text {loss }}=.83\right)$, whereas loss-framed messages evoked more negative affect $\left(M_{\text {gain }}=3.12, \mathrm{SD}_{\text {gain }}=.93 ; M_{\mathrm{loss}}=3.46, \mathrm{SD}_{\mathrm{loss}}=.98\right)$. These findings support Hypotheses 1 and 3 . Also, gainframed information was more readily accepted than loss-framed information, as in Experiment $1\left(M_{\text {gain }}=5.71\right.$, $\left.\mathrm{SD}_{\text {gain }}=.53 ; M_{\text {loss }}=5.47, \mathrm{SD}_{\text {loss }}=.70\right)$, and resulted in more positive attitudes $\left(M_{\text {gain }}=5.53, \mathrm{SD}_{\text {gain }}=.66 ; M_{\text {loss }}=5.32\right.$, $\left.\mathrm{SD}_{\text {loss }}=.70\right)$. There was no significant effect of frame on intentions $\left(M_{\text {gain }}=4.21, \mathrm{SD}_{\text {gain }}=1.39 ; M_{\text {loss }}=4.17\right.$, $\mathrm{SD}_{\text {loss }}=1.14$ ) (see Table 4).

Table 3. Correlations between baseline intention, positive affect, negative affect, attitude and intention

\begin{tabular}{|c|c|c|c|c|c|}
\hline & Baseline intention & Positive affect & Negative affect & Information acceptance & Attitude \\
\hline Positive affect & .00 & & & & \\
\hline Negative affect & .05 & $-.31^{* *}$ & - & & \\
\hline Information acceptance & $.18^{*}$ & $.31^{* *}$ & -.12 & - & \\
\hline Attitude & $.36^{* *}$ & $.47^{* *}$ & -.17 & $.58^{* * *}$ & - \\
\hline Intention & $.65^{* * *}$ & .02 & $.27^{* *}$ & $.20^{*}$ & $.35^{* * *}$ \\
\hline
\end{tabular}

${ }^{*} p<.05 ;{ }^{* *} p<.01 ;{ }^{* * *} p<.001$. 
Table 4. Results of the linear regression analyses: Effects of frame on positive affect, negative affect, information acceptance, attitude and intention, controlled for baseline intention

\begin{tabular}{lcr}
\hline & \multicolumn{2}{c}{ Effect of frame $^{\mathrm{a}}$} \\
\cline { 2 - 3 } & \multicolumn{1}{c}{$B$} & SE $B$ \\
\hline Positive affect & $-.39^{* *}$ & .15 \\
Negative affect & $.36^{*}$ & .17 \\
Information acceptance & $-.25^{*}$ & .11 \\
Attitude & $-.23^{*}$ & .11 \\
Intention & -.11 & .17 \\
\hline
\end{tabular}

${ }^{\mathrm{a} C}$ Coded as $0=$ gain frame, $1=$ loss frame. ${ }^{*} p<.05 ;{ }^{* *} p<.01$.

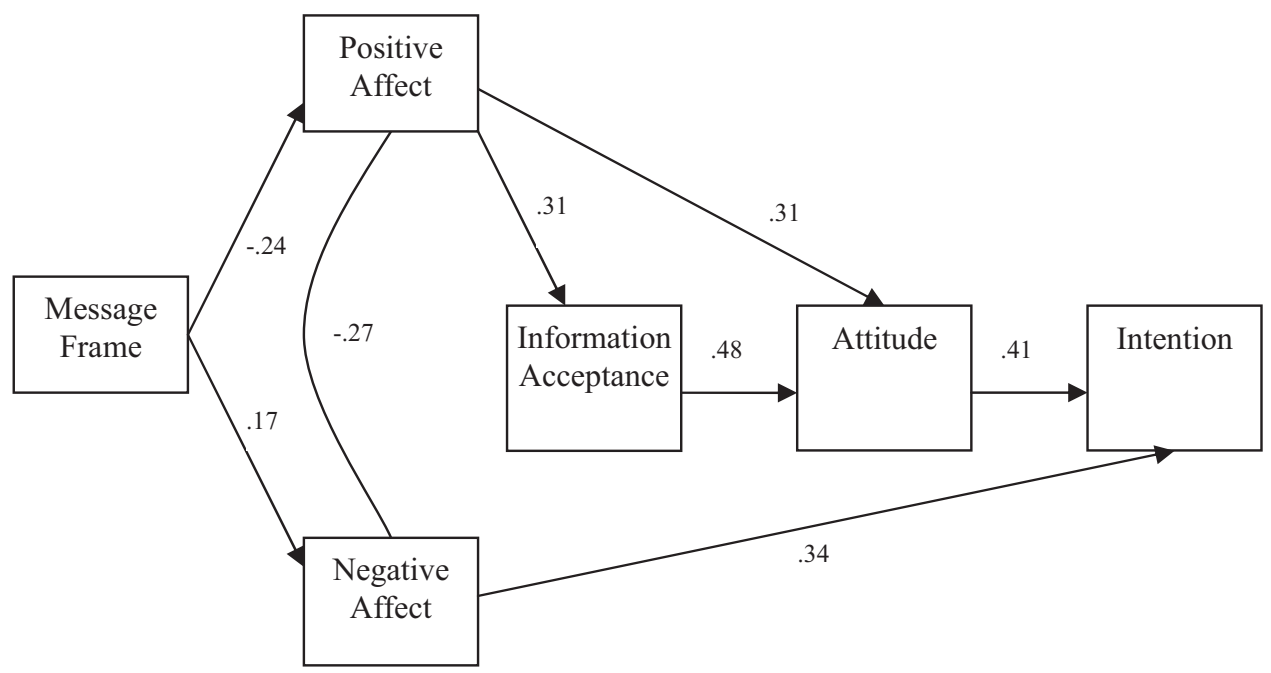

Figure 1. Path model showing positive affect as a predictor of information acceptance and attitude, and negative affect as a predictor of intention. All paths are significant at the $p=.05$ level

\section{Path Model}

In addition to the correlation analyses and regression analyses presented above, we used Structural Equation Modelling to get a clearer picture of our results. To investigate the influence that positive and negative affect had on the other outcome measures, we investigated several path models. Figure 1 shows the path model with the most favourable model fit, in which message frame predicts both positive and negative affect, positive affect predicts information acceptance and attitude while negative affect has a direct effect on intention. Analyses using Structural Equation Modelling showed that this model fitted the data well, $\chi^{2}(7)=3.458, p=.8396 ; \mathrm{CFI}=1.000 ; \mathrm{RMSEA}=.000 ; \mathrm{SRMR}=.030 .{ }^{1}$ To obtain an additional test of our model, an extended model was tested in which paths from frame to positive affect, negative affect, information acceptance, attitude and intention were added, as were paths from positive and negative affect to information acceptance, attitude and intention. This extended model did not have a significantly greater model fit than the model in Figure 1, $\Delta \chi^{2}(6)=3.458, p=$ n.s. The paths from frame to information acceptance, attitude and intention were not significant, and neither were the paths from positive affect to intention, or the paths from negative affect to information acceptance and attitude.

${ }^{1}$ When $\chi^{2}<\mathrm{df}$, as is the case with the model in Figure 1, the CFI-value is 1.000 and the RMSEA-value is .000. Note that this does not necessarily mean that model fit is perfect (Kline, 2005). It does, however, indicate excellent model fit. 


\section{Mediation Analyses}

The path model outlined above strongly suggests that message framing exerted its influence on the outcome measures through positive and negative affect. To formally test whether the effects of frame on information acceptance and attitude were mediated by positive affect (Hypothesis 2) and whether negative affect mediated an effect of frame on intention (Hypothesis 4), we performed mediation analyses. In these analyses, we again controlled for baseline intention.

With regards to Hypothesis 2, Table 4 shows that frame had a significant effect on positive affect and information acceptance. A regression analysis with frame and positive affect as independent variables and information acceptance as the dependent variable revealed that positive affect had a significant effect on information acceptance, $B=.21$, $t(124)=3.30, p=.001$, while the effect of frame was reduced to non-significance, $B=-.17, t(124)=-1.59, p=.11$. A Sobel's $Z$-tests revealed that the mediation was significant, $Z=-2.04, p<.05$. Table 4 also shows that frame had a significant effect on attitude. A regression analysis with frame and positive affect as the independent variables and attitude as the dependent variable revealed that positive affect had a significant effect on attitude, $B=.37, t(124)=6.03, p<.001$. At the same time, the effect of frame was reduced to non-significance, $\mathrm{B}=-.09, t(124)=-.88, p=.38$. A Sobel's $Z$-test revealed that the mediation was significant, $Z=-2.45, p<.05$.

With regards to Hypothesis 4, the results of the correlation analysis showed that negative affect was associated with intention. However, the path model in Figure 1 shows that positive affect also had an effect on intention, although indirectly — through attitude. This might explain why frame did not have a significant total effect on intention (Table 4): Intention is affected both by positive affect as a result of gain-framed information and by negative affect as a result of lossframed information. However, according to MacKinnon et al. (2002), there can still be mediation, even in the absence of a significant total effect of the independent variable on the dependent variable. MacKinnon et al. therefore propose the test of joint significance of the two effects comprising the mediation effect (MacKinnon et al., 2002). In this approach, a variable functions as a mediator when two conditions are met: (1) the independent variable has a significant effect on the mediator and (2) the mediator is significantly associated with the dependent variable when the other independent variables are controlled for. Thus, as compared to the traditional Baron \& Kenny approach, the condition that the independent variable has a total effect on the dependent variable is dropped. Because we hypothesized that framing exerts a different influence on positive and negative affect (gain-framed information results in more positive affect than loss-framed information, but in less negative affect) and positive and negative affect exert a similar influence on intention, we do not assume the existence of a total effect of framing on intention.

Table 4 shows that frame had a significant effect on negative affect. A third regression analysis was performed to investigate whether negative affect had a significant effect on intention when controlled for frame and baseline intention. This proved to be the case, $B=.33, t(124)=5.98, p<.001$. A Sobel's $Z$-tests revealed that the mediation was significant, $Z=1.97, p<.05$.

\section{Discussion}

The results of Experiment 2 confirmed Hypotheses 1 and 2 and replicated the finding from Experiment 1 that gain-framed information lead to greater levels of positive affect, which was positively associated with information acceptance. In addition, an effect of positive affect on attitude was found. In Experiment 2 we further found that loss-framed information resulted in greater levels of negative affect and that negative affect lead to stronger intentions to reduce salt intake, supporting Hypotheses 3 and 4.

We propose that these findings suggest that gain- and loss-framed messages not only exert their influence through separate mechanisms (positive and negative affect), but also that these mechanisms might have different effects on different outcome measures.

\section{GENERAL DISCUSSION}

The aim of the present research was to investigate whether information that is gain- versus loss-framed gives rise to different levels of positive and negative feelings and whether these feelings exert an influence on persuasion. The results of two experiments showed that gain-framed information evoked greater levels of positive affect in recipients than loss- 
framed information, and that positive affect was positively associated with information acceptance, resulting in greater levels of information acceptance in the gain-framed condition. In Experiment 2, positive affect also influenced participants' attitudes, resulting in more positive attitudes in the gain-framed condition as compared to the loss-framed condition. The results of Experiment 2 furthermore showed that loss-framed information resulted in greater levels of negative affect than gain-framed information and that negative affect, while not being associated with information acceptance or attitude, had a significant effect on intention.

These results suggest that positive and negative affective reactions are of great importance to the study of message framing in particular and persuasion in general. They further suggest that gain- and loss-framed messages exert their influence through separate mechanisms (positive and negative affect). In fact, although more research is needed to arrive at definitive conclusions, it seems that gain-framed information can have an effect on information acceptance and attitude through positive affect, exerting a persuading influence, whereas loss-framed information might be more likely to have an effect on intention through negative affect, exerting a motivating influence.

Our results also show that, since framing has opposing effects on positive and negative affect, and positive and negative affect both contribute to persuasion, it can be difficult to find consistent main effects of framing on behaviour. In this regard, our results might be exemplary of the message-framing literature as a whole. Besides the occasional null-findings that have been reported (Brug, Ruiter, \& Van Assema, 2003; Jones, Sinclair, \& Courneya, 2003; Steffen, Sternberg, Teegarden, \& Shepherd, 1994), recent meta-analyses provide evidence that gain- and loss-framed messages do not affect psychological and behavioural outcomes in a consistent and predictable way across all populations (O'Keefe \& Jensen, 2006, 2007). Our findings add to the literature, however, by implying that message-framing research should pay specific attention to the underlying mechanisms of framing effects and to the outcome measures being used. In a recent metaanalysis, for instance, O'Keefe and Jensen included dozens of studies, without differentiating between effects found on attitude, intention or behaviour. In fact, when multiple indices of persuasion were available, they averaged the effects, yielding a single summary. A meta-analysis of this kind, focusing on outcomes instead of processes and not differentiating between outcome measures, obscures the possibility that gain- and loss-framed messages may exert their influence on persuasion through different pathways (Shen \& Dillard, 2007). The results of the present research suggest that future metaanalyses should analyse the effects of framing on information acceptance, attitude, intention and behaviour separately.

In addition, research that does not distinguish between outcome measures might be unable to reveal effects that are relevant to health-promotion professionals. For instance, the effect of frame on information acceptance, also found in previous studies (Latimer et al., 2008; Reinhart, Marshall, Feeley, \& Tutzauer, 2007; Schneider et al., 2001b; Smith, 1996), might have direct implications for health-promoting materials on the Internet. Given the growing practice to use the Internet as a medium for health-promoting information and the importance of increasing people's exposure to this information (i.e. drawing attention and keeping recipients interested; see for instance Crutzen et al., 2008), information acceptance might be of critical importance. After all, people seeking information on the Internet are most likely to select information that seems relevant, interesting, and trustworthy. Future research should investigate whether message framing can be used to increase exposure in an online setting.

In the present article, we have argued that, to better understand message-framing effects, it is important to investigate the pathways by which gain- and loss-framed messages exert their influence. From an applied perspective, however, it is also important to know under which circumstances gain- or loss-framed information is more effective. Future research should thus clarify the circumstances under which one pathway dominates over the other. Perhaps differences in the types of behaviour advocated by the message could influence which affective pathway dominates. For young people, some health-promoting behaviours, like physical activity, might be associated with positive feelings. It might be, then, that for those types of behaviour the positive affect pathway dominates. Other health-promoting behaviours, like breast selfexamination, might be associated with negative feelings, like fear. For these types of behaviours, the negative affective pathway might dominate (cf. Rothman \& Salovey, 1997). One additional possibility is that efficacy expectations might be crucial in determining the outcome of message-framing effects. In line with findings from the fear-appeal literature (Witte, 1992, 1994), a mediating effect of negative affect might be most likely when recipients perceive a high efficacy. This might be able to explain the results of a recent study, which found that loss-framed anti-smoking messages resulted in a stronger intention to quit smoking than gain-framed messages, but only for recipients who had high self-efficacy to quit smoking (Van 't Riet et al., 2008). Another possibility is that the likelihood that one pathway dominates over the other depends on recipients' approach and avoidance orientation. Recently, several studies have found that gain-framed information was more persuasive for recipients with a predominant approach orientation (Behavioural Activation System-BAS), while 
loss-framed information was more persuasive for recipients with a predominant avoidance orientation (Behavioural Inhibition System - BIS) (Gerend \& Shepherd, 2007; Mann, Sherman, \& Updegraff, 2004; Updegraff, Sherman, Luyster, \& Mann, 2007). Our results suggest that it would be interesting to investigate whether these findings can be explained by positive and negative affect. There is evidence from a study of persuasion that BAS activity correlates with positive affective responses to a message, while BIS activity correlates with negative emotional responses to a message (Dillard \& Peck, 2001). One could therefore expect that gain-framed information is more persuasive for recipients with high BAS levels, because, among these recipients, gain-framed information is particularly likely to evoke positive affect. Also, it could be expected that loss-framed information is more persuasive for recipients with high BIS levels, because, among these recipients, loss-framed information is particularly likely to evoke negative affect.

\section{Limitations}

The present research was subject to several limitations. First, because we did not include a no-framing control group, it is difficult to infer whether the gain-framed information increased positive affect or whether the loss-framed information decreased positive affect. However, information that neither stresses the benefits of healthy behaviour, nor the costs of unhealthy behaviour is likely to be incomparable to the health-promoting information we used in the gain-framed and lossframed conditions. This might be one of the reasons why most message-framing studies compare gain- versus loss-frames and do not include a no-frame control group.

Another issue that warrants attention is the fact that we assessed diffuse affect instead of specific emotions. In Experiment 2, four items assessed general positive affective reactions (i.e. happy, relieved, optimistic, content) and four items assessed general negative affective reactions (i.e. sad, afraid, uncomfortable, tense). Doing this, we used what Van der Pligt et al. (1998; p. 57) called 'a rather crude dichotomy of positive versus negative affect'. In fact, these authors argue that, instead of using these holistic measures, it is essential to distinguish between various, more specific, affective reactions. A limitation of this research, then, is that we did not differentiate more specifically between possibly relevant emotions, like anger, fear, happiness, and relief. Dillard and Peck (2001), for instance, investigated whether the content of eight public service announcements (PSA's) elicited anger, fear, sadness, guilt, contentment, surprise and happiness. In addition, they investigated which emotions were predictive of perceived effectiveness. The advantage of this approach is that it makes it possible to investigate more specifically which types of information lead to which emotion. It could then be investigated, for instance, whether gain-framed health promoting messages result in happiness, elation, relief or contentment and whether loss-framed messages result in sadness, disappointment, guilt or fear. Also, since different emotions are associated with different 'action tendencies' (Frijda, 2007), it might lead to more specific hypotheses concerning which emotions affect behaviour and why. One could hypothesize, for instance, that fear can increase intentions to engage in healthy behaviour, whereas disappointment could lead to decreased motivation. Future research should investigate this possibility. Lastly, it is unclear from the present study whether cognitive reactions in addition to affective reactions can mediate the persuasiveness of gain- and loss-framed messages, as proposed in cognitive response theory (Petty, Ostrom, \& Block, 1981). Future studies could employ thought listing procedures to investigate the influence of cognitive reactions to gain- and loss-framed messages. ${ }^{2}$

\section{Conclusion}

Despite the limitations noted above, the results of the present research suggest that both positive and negative feelings may be of great importance in the persuasion process and may be particular helpful to explain the occurrence of framing effects. Whereas positive affect as a result of gain-framed information can contribute to high levels of information acceptance and a positive attitude, thereby exerting a persuasive influence, negative affect as a result of loss-framed information can contribute directly to intention, thereby exerting a motivating influence. These findings suggest that framing exerts influence on persuasion through two different pathways: Positive and negative affect.

\footnotetext{
${ }^{2}$ Another point that could be made concerns the fact that two of the positive affect items used in Experiment 2, 'optimistic' and 'content', do not cover purely affective states but might also capture cognitive reactions. Therefore, we repeated the analyses excluding these items from the positive affect measure. This yielded similar results and identical conclusions.
} 


\section{ACKNOWLEDGEMENTS}

This research was funded by ZonMW - the Netherlands Organisation for Health Research and Development (6100.0005).

The authors thank the editor and two anonymous reviewers for their very helpful comments and Claire Jeukens and Michelle Stoel for their assistance with the data collection.

\section{REFERENCES}

Baron, R. M. \& Kenny, D. A. (1986). The moderator-mediator variable distinction in social psychological research: Conceptual, strategic and statistical considerations. Journal of Personality and Social Psychology, 51, 1173-1182.

Bless, H. \& Schwartz, N. (1999). Sufficient and necessary conditions in dual-process models. In S. Chaiken, \& Y. Trope (Eds.), Dual process theories in social psychology. New York: Guilford Press.

Broemer, P. (2004). Ease of imagination moderates reactions to differently framed health messages. European Journal of Social Psychology, 34, 103-119.

Brown, S. P., Homer, P. M., \& Inman, J. J. (1998). A meta-analysis of relationships between ad-evoked feelings and advertising responses. Journal of Marketing Research, 35, 114-126.

Brug, J., Ruiter, R. A. C., \& Van Assema, P. (2003). The (ir)relevance of framing nutrition education messages. Nutrition and Health, 17, 9-20.

Cacioppo, J. T. \& Berntson, G. G. (1994). Relationship between attitudes and evaluative space: A critical review, with emphasis on the separability of positive and negative substrates. Psychological Bulletin, 115, 401-423.

Carey, C. (1994). Rhetorical means of persuasion. In I. Worthington (Ed.), Persuasion: Greek rhetoric in action (pp. 26-45). London: Routledge.

Chang, C. (2005). The moderating influence of ad framing for ad-self-congruency effects. Psychology and Marketing, 22, 955-968.

Cox, D. \& Cox, A. D. (2001). Communicating the consequences of early detection: The role of evidence and framing. Journal of Marketing, 65, 91-103.

Cox, A. D., Cox, D., \& Zimet, G. (2006). Understanding consumer responses to product risk information. Journal of Marketing, 70, 7991.

Crutzen, R., de Nooijer, J., Brouwer, W., Oenema, A., Brug, J., \& de Vries, N. K. (2008). Internet-delivered interventions aimed at adolescents: A Delphi study on dissemination and exposure. Health Education Research, 23, 427-439.

De Hoog, N., Stroebe, W., \& De Wit, J. B. F. (2008). The processing of fear-arousing communications: How biased processing leads to persuasion. Social Influence, 3, 84-113.

Dillard, J. P. \& Meijnders, A. (2002). Persuasion and the structure of affect. In J. P. Dillard \& M. Pfau (Eds.), The persuasion handbook: Developments in theory and practice (pp. 309-327). Thousand Oaks, CA: Sage.

Dillard, J. P. \& Peck, E. (2001). Persuasion and the structure of affect: Dual systems and discrete emotions as complementary models. Human Communication Research, 27, 38-68.

Dillard, J. P., Weber, K. M., \& Vail, R. G. (2007). The relationship between the perceived and the actual effectiveness of persuasive messages: A meta-analysis with implications for formative campaign research. Journal of Communication, 57, 613-631.

Eagly, A. H. \& Chaiken, S. (1993). The psychology of attitudes. Fort Worth, TX: Harcourt Brace Jovanovich.

Forgas, J. P. (1995). Mood and judgment: The affect infusion model (AIM). Psychological Bulletin, 117, 39-66.

Forgas, J. P. (2007). When sad is better than happy: Negative affect can improve the quality and effectiveness of persuasive messages and social influence strategies. Journal of Experimental Social Psychology, 43, 513-528.

Fredrickson, B. L. \& Branigan, C. A. (2005). Positive emotions broaden the scope of attention and thought-action repertoires. Cognition and Emotion, 19, 313-332.

Fredrickson, B. L. \& Losada, M. F. (2005). Positive affect and the complex dynamics of human flourishing. American Psychologist, 60, 678-686.

Frijda, N. H. (1986). The emotions. New York: Camebridge University Press.

Frijda, N. H. (2007). The laws of emotion. Mahwah, NJ: Lawrence Erlbaum.

Gerend, M. A. \& Cullen, M. (2008). Effects of message framing and temporal context on college student drinking behaviour. Journal of Experimental Social Psychology, 44, 1167-1173.

Gerend, M. A. \& Shepherd, J. E. (2007). Using message framing to promote acceptance of the human papillomavirus vaccine. Health Psychology, 26, 745-752.

Isen, A. M., Daubman, K. A., \& Nowicki, G. P. (1987). Positive affect facilitates creative problem solving. Journal of Personality and Social Psychology, 52, 1122-1131.

Isen, A. M., Nygren, T. E., \& Ashby, F. G. (1988). Influence of positive affect on the subjective utility of gains and losses: It is just not worth the risk. Journal of Personality and Social Psychology, 55, 710-717. 
Jones, L. W., Sinclair, R. C., \& Courneya, K. S. (2003). The effects of source credibility and message framing on exercise intentions, behaviours and attitudes: An integration of the elaboration likelihood model and prospect theory. Journal of Applied Social Psychology, 33, 179-196.

Kahneman, D. (2003). A perspective on judgement and choice: Mapping bounded rationality. American Psychologist, 58, $697-720$.

Kahneman, D. \& Tversky, A. (1984). Choices, values, and frames. American Psychologist, 39, 341-350.

Kline, R. B. (2005). Principles and practice of structural equation modeling. New York: The Guilford Press.

Latimer, A. E., Rench, T. A., Rivers, S. E., Katulak, N. A., Materese, S. A., Cadmus, L., et al. (2008). Promoting participation in physical activity using framed messages: An application of prospect theory. British Journal of Health Psychology, 13, 659-682.

Lazarus, R. S. (1991). Emotion and adaptation. New York: Oxford University Press.

MacKenzie, S. B., Lutz, R. J., \& Belch, G. E. (1986). The role of attitude toward the ad as a mediator of advertising effectiveness: A test of competing explanations. Journal of Marketing Research, 18, 318-331.

MacKinnon, D. P., Lockwood, C. M., Hoffman, J. M., West, S. G., \& Sheets, V. (2002). A comparison of methods to test mediation and other intervening variable effects. Psychological Methods, 7, 83-104.

Mann, T., Sherman, D., \& Updegraff, J. (2004). Dispositional motivations and message framing: A test of the congruency hypothesis in college students. Health Psychology, 23, 330-334.

Millar, M. G. \& Millar, K. (2000). Promoting safe driving behaviour: The influence of message framing and issue involvement. Journal of Applied Social Psychology, 30, 853-866.

Mongeau, P. (1998). Another look at fear arousing messages. In M. Allen, \& R. Preiss (Eds.), Persuasion: Advances through metaanalysis (pp. 53-68). Cresskill, NJ: Hampton Press.

O'Keefe, D. J. \& Jensen, J. D. (2006). The advantages of compliance or the disadvantages of noncompliance? A meta-analytic review of the relative persuasive effectiveness of gain-framed and loss-framed messages. In C. S. Beck (Ed.), Communication yearbook (Vol. 30, 1-44). Mahwah, NJ: Lawrence Erlbaum Associates.

O'Keefe, D. J. \& Jensen, J. D. (2007). The relative persuasiveness of gain-framed and loss-framed messages for encouraging disease prevention behaviours: A meta-analytic review. Journal of Health Communication, 12, 623-644.

Petty, R. E., Ostrom, T. M., \& Block T. C. (Eds.). (1981). Cognitive responses in persuasion. Hillsdale, NJ: Lawrence Erlbaum Associates.

Reinhart, A. M., Marshall, H. M., Feeley, T. H., \& Tutzauer, F. (2007). The persuasive effects of message framing in organ donation: The mediating role of psychological reactance. Communication Monographs, 74, 229-255.

Rogers, R. W. (1983). Cognitive and physiological processes in fear appeals and attitude change: A revised theory of protection motivation. In J. T. Cacioppo \& R. E. Petty (Eds.), Social psychophysiology: A sourcebook (pp. 153-176). New York: Guilford.

Rothman, A. J., \& Salovey, P. (1997). Shaping perceptions to motivate healthy behaviour: The role of message framing. Psychological Bulletin, 121, 3-19.

Ruiter, R. A. C., Abraham, C., \& Kok, G. (2001). Scary warnings and rational precautions: A review of the psychology of fear appeals. Psychology and Health, 16, 613-630.

Schneider, T. R., Salovey, P., Apanovitch, A. M., Pizarro, J., McCarthy, D., Zullo, J., et al. (2001a). The effects of message framing and ethnic targeting on mammography use among low-income women. Health Psychology, 20, 256-266.

Schneider, T. R., Salovey, P., Pallonen, U., Mundorf, N., Smith, N. F., Steward, W. T. (2001b). Visual and auditory message framing effects on tobacco smoking. Journal of Applied Social Psychology, 31, 667-682.

Schwarz, N. \& Clore, G. L. (2003). Mood as information: 20 years later. Psychological Inquiry, 14, $296-303$.

Shen, L. \& Dillard, J. P. (2007). The influence of behavioural inhibition/approach systems and message framing on the processing of persuasive health messages. Communication Research, 34, 433-467.

Sinclair, R. C., Mark, M. M., \& Clore, G. L. (1994). Mood-related persuasion depends on (mis)attributions. Social Cognition, 12, 309326.

Smith, G. E. (1996). Framing in advertising and the moderating impact of consumer education. Journal of Advertising Research, 36, 4964.

Steffen, V. J., Sternberg, L., Teegarden, L. A., \& Sheperd, K. (1994). Practice and persuasive frame: Effects on beliefs, intention, and performance of a cancer self-examination. Journal of Applied Social Psychology, 24, 897-925.

Updegraff, J. A., Sherman, D. K., Luyster, F. S., \& Mann, T. L. (2007). The effects of message quality and congruency on perceptions of tailored health communications. Journal of Experimental Social Psychology, 43, 249-257.

Van 't Riet, J., Ruiter, R. A. C., Werrij, M. Q., \& De Vries, H. (2008). The influence of self-efficacy on the effects of framed health messages. European Journal of Social Psychology, 38, 800-809.

Van der Pligt, J., Zeelenberg, M., van Dijk, W. W., de Vries, N. K., \& Richard, R. (1998). Affect, attitudes and decisions: Let's be more specific. European Review of Social Psychology, 8, 33-66.

Witte, K. (1992). Putting the fear back into fear appeals: The extended parallel process model. Communication Monographs, 59, 329349.

Witte, K. (1994). Fear control and danger control: A test of the extended parallel process model (EPPM). Communication Monographs, $61,113-134$.

Witte, K. \& Allen, M., (2000). A meta-analysis of fear appeals: Implications for effective public health campaigns. Health Education and Behaviour, 27, 591-615. 


\section{APPENDIX: GAIN- AND LOSS-FRAMED MESSAGES}

\section{Gain-Framed Message}

The Advantages of Little Salt

According to a recent report by the Dutch Health Council eating little salt is a sensible thing to do. The healthy thing to do is to eat less than six grams of salt each day. Most people eat way too much salt. The Dutch Society of Consumers estimates that the Dutch eat $10-12 \mathrm{~g}$ of salt per day on average.

\section{Hypertension}

Scientific research shows that eating little salt may contribute to a normal and healthy blood pressure. If the Dutch would start to eat less salt, the incidence of hypertension in the Netherlands would fall.

\section{Cutting Back on Salt is Good for Your Health}

Cutting back on salt is the most important way to prevent hypertension, even more important than exercising or quitting smoking. Having a normal blood pressure decreases your chance of getting a stroke or a heart attack.

\section{Other Advantages of Cutting Back on Salt}

- It decreases the risk of stomach cancer.

- It decreases the risk of osteoporosis.

- It decreases the risk of renal stones.

In short, cutting back on salt can improve your health dramatically. Take this chance, cut back on salt!

\section{Loss-Framed Message}

\section{The Dangers of Too Much Salt}

According to a recent report by the Dutch Health Council eating too much salt is dangerous. Eating more than six grams of salt each day entails many risks. Most people eat way too much salt. The Dutch Society of Consumers estimates that the Dutch eat $10-12 \mathrm{~g}$ of salt per day on average.

\section{Hypertension}

Scientific research shows that a salty diet may lead to hypertension. If the Dutch continue to eat too much salt, the incidence of hypertension in the Netherlands will rise.

\section{Too Much Salt is Bad for Your Health}

A salty diet is the most important cause of hypertension, even more important than lack of exercise or smoking. Hypertension can lead to a much greater risk of a stroke or a heart attack. 
Other Disadvantages of Too Much Salt

- It increases the risk of stomach cancer.

- It increases the risk of osteoporosis.

- It increases the risk of renal stones.

In short, eating too much salt can damage your health seriously. Avoid these dangers, be careful with salt! 